The Free Internet Journal

for Organic Chemistry
Review

Arkivoc 2019, part i, 1-17

Organic Chemistry

On the Winstein rearrangement: equilibrium and mechanism

\author{
Amy A. Ott and Joseph J. Topczewski* \\ Department of Chemistry, University of Minnesota Twin Cities, Minneapolis, Minnesota 55455, United States \\ Email:jtopczew@umn.edu
}

Received 11-19-2018

Accepted 01-22-2019

Published on line 03-30-2019

\title{
Abstract
}

Allylic azides are underutilized in organic synthesis when compared to other organic azides or other allylic functionality. This is likely because allylic azides rearrange at room temperature, resulting in a potentially complex mixture of azides. This rearrangement has been termed the Winstein rearrangement. Understanding the mechanism and basic principles governing the allylic azide equilibrium may aid in developing applications for these molecules based on either alkene or azide functionalization. Presented herein is a compilation of the key observations regarding the nature of the allylic azide rearrangement. Mechanistic considerations are explicitly addressed with key examples from the literature.

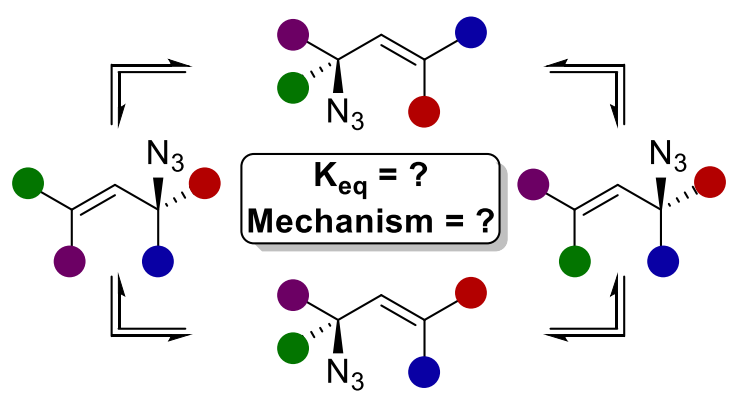

Keywords: Azides, mechanism, sigmatropic, equilibrium 


\section{Table of Contents}

1. Introduction

2. Winstein's Report of the Allylic Azide Rearrangement

3. Factors Affecting the Equilibrium

\subsection{Conjugation}

3.2. Steric effects: syn-pentane interactions

3.3. Stereoelectronic effects

4. Mechanistic Insights

4.1. Evidence for stereospecificity

4.2. Computational investigations

4.3. ${ }^{15} \mathrm{~N}$ Labeling study

4.4. Ionic and catalyzed pathways for the Winstein rearrangement

5. Conclusions

\section{Introduction}

Nitrogen containing functional groups are prevalent in numerous impactful molecules, including molecules for medicinal chemistry, polymer chemistry, chemical biology, and material science applications. As such, there are various well developed synthetic approaches to access many nitrogen-containing molecules. Organic azides have a long history in synthesis and azides can be used to access a range of nitrogenous functionality (Scheme 1). Therefore, synthetic methods that use organic azides have remained prominent for many nitrogenous targets. ${ }^{1-3}$ While many classes of azides have been extensively studied and utilized, there has been relatively sparse use of allylic azides in the literature. This is likely due to allylic azides' propensity to exist as a mixture of isomers. ${ }^{4}$ Excitingly, both the alkene and azide provide orthogonal handles for further manipulation, and thus the ability to efficiently utilize allylic azides in synthesis would be highly desirable. In this account, we will discuss the allylic azide rearrangement in terms of equilibrium and mechanism. This is not intended to be an extensive review and synthetic applications are not explicitly addressed. Understanding the basic principles regarding this rearrangement may be useful to advance synthetic applications for these molecules.

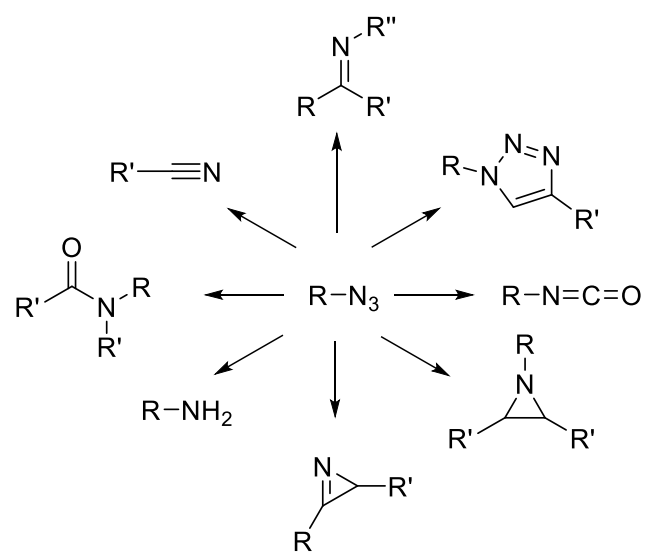

Scheme 1. Utility of organic azides. 


\section{Winstein's Report of the Allylic Azide Rearrangement}

The allylic azide rearrangement was first documented by Winstein and co-workers in 1960 (Scheme 2a)..$^{4}$ In this seminal report, the authors studied crotyl and prenyl azide. These compounds were isolated as individual isomers that reformed a mixture under ambient conditions. When at equilibrium, both crotyl and prenyl azide consist primarily of the isomer with the more substituted alkene (ratios of 64:46 and 75:25 respectively). This is the first indication that the stability of the alkene plays a critical role in determining the equilibrium ratio, which would be confirmed later.

a)

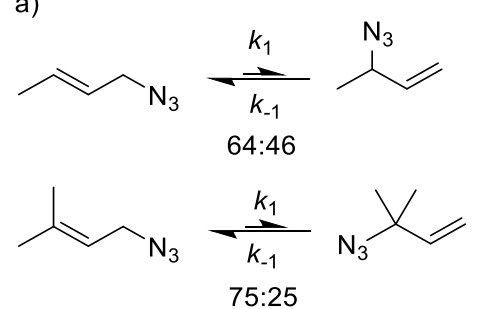

\begin{tabular}{|c|c|c|}
\hline \multirow[b]{2}{*}{ solvent } & (1) & (2) \\
\hline & $\overline{10^{5}\left(k_{1}+k_{-1}\right) \mathrm{s}^{-1}}$ & $\overline{10^{5}\left(k_{1}+k_{-1}\right) \mathrm{s}^{-1}}$ \\
\hline$n-\mathrm{C}_{5} \mathrm{H}_{12}$ & 1.88 & 4.93 \\
\hline $\mathrm{Et}_{2} \mathrm{O}$ & 4.28 & 11.1 \\
\hline $\mathrm{EtOH}$ & 7.18 & 24.1 \\
\hline $70 \% \mathrm{Me}_{2} \mathrm{CO}$ & 24.9 & 90.6 \\
\hline
\end{tabular}

Scheme 2. Winstein rearrangment.

The rate of isomerization was measured by Winstein and co-workers. For these simple azides, the half-life at room temperature is on the order of a few hours. The isomerization was not sensitive to changes in solvent across a large range of dielectric constants (subset provided, Scheme $2 \mathrm{~b}$ ). The rate is measured as the sum of the forward and reverse rearrangement ( $k_{1}$ and $k_{-1}$ respectively). For prenyl azide, the rate constant in pentane was $4.93 \times 10^{-5} \mathrm{~s}^{-1}$ while the rate constant in $70 \%$ aqueous acetone was $90.6 \times 10^{-5} \mathrm{~s}^{-1}$, less than a twenty-fold rate enhancement. These results highlight the relatively small increase in rate constant relative to increasing solvent dielectric constant. For polar reactions that are more sensitive to solvent effects, a difference of several orders of magnitude would be expected. A similar trend was observed with crotyl azide. The insensitivity of the rate of rearrangement to solvent effects indicates a lack of charge build-up in the transition state. ${ }^{4}$ This evidence implies a cyclic and possibly sigmatropic rearrangement. A few years later, Le Noble investigated the effect of pressure on the allylic azide rearrangement and those results were consistent with a cyclic mechanism. ${ }^{5}$ Other experiments are discussed below that further support the initially proposed mechanism.

One can compare the reported rates of rearrangement for prenyl azide and crotyl azide (Scheme $2 b$ ). In all solvents, prenyl azide rearranged at an increased rate relative to crotyl azide. In pentane and in $70 \%$ aqueous. acetone, this rate enhancement was by a factor of 2.6 and 3.6, respectively. This observation demonstrates an enhanced rate of reactivity due to the additional methyl substituent. ${ }^{4} \mathrm{~A}$ similar effect has been observed on other systems (vide infra), indicating that increased electron density of the alkene increases the rate of the Winstein rearrangement.

In retrospect, the allylic azide rearrangement could have been discovered by VanderWerf and Heasley. ${ }^{6}$ Two products were isolated from opening butadiene monoxide with sodium azide followed by subsequent reduction to the corresponding amine. At the time, this mixture was attributed to competitive epoxide opening via $\mathrm{S}_{\mathrm{N}} 2$ and $\mathrm{S}_{\mathrm{N}} 2^{\prime}$ pathways (Scheme 3). The authors did speculate on the possibility of an allylic rearrangement and noted it was less probable than competitive ring opening. 


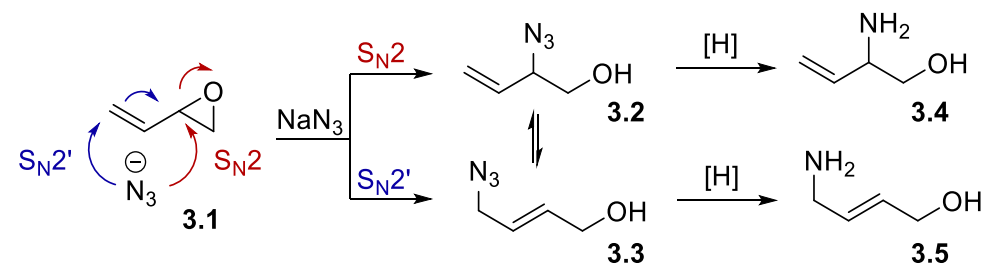

Scheme 3. Epoxide Opening with $\mathrm{NaN}_{3}$.

Since the seminal report approximately 60 years ago, there has been only limited synthetic applications involving allylic azides. This is likely due to the potential for a complex mixture of azide isomers under ambient conditions. Described below are factors that could be used to control the equilibrium ratio and key mechanistic features that have been uncovered since Winstein's seminal report.

\section{Factors Affecting the Equilibrium}

Since the first report of the allylic azide rearrangement, there have been a few key observations regarding equilibrium ratios of allylic azides. Many of these observations can be combined to make sensible predictions regarding the relative abundance of azide isomers that would be present in the mixture. A simple example would be to state that the isomer with the more substituted alkene tends to be favored (Scheme 2a). Depending on neighboring functionality, some azides exist as a complex mixture of up to four alkene isomers (distal or proximal, and $E$ or Z), while others can be isolated and used as a single compound. The following sections provide some insight on how proximal functionality may bias the equilibrium constant of the Winstein rearrangement. It should be noted that because of the Curtin-Hammett principle the major equilibrium isomer is not necessarily the isomer that will react in a functionalization reaction.

\subsection{Conjugation}

Conjugation is known as a fundamental stabilizing phenomena, and it can significantly bias the allylic azide equilibrium. Classically, the effect of conjugation was measured by comparing heats of hydrogenation (Scheme 4). For example, the reduction of two molecules of 1-butene provides more energy $\left(\Delta H^{\circ}=-60.6 \mathrm{kcal}\right.$ $\left.\mathrm{mol}^{-1}\right)$, than the reduction of 1,3-butadiene $\left(\Delta H^{\circ}=-57.1 \mathrm{kcal} \mathrm{mol}^{-1}\right) .{ }^{7}$ The $3.5 \mathrm{kcal} \mathrm{mol}^{-1}$ energy difference is due to a stabilizing interaction between the alkenes. This conjugation energy is presumably at play with allylic azides and explains why a mixture of isomers is not always observed when a proximal conjugating group is present.

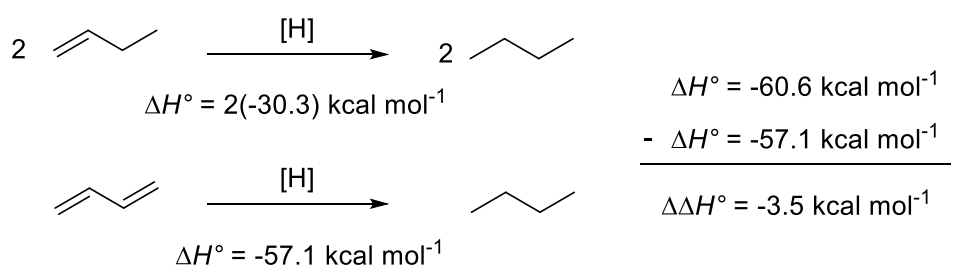

Scheme 4. Stabilization energy of conjugation.

Hassner synthesized cinnamyl azide from the corresponding alcohol and reported the product as a single isomer (Scheme 5a). ${ }^{8}$ Our lab also observed the same outcome when synthesizing cinnamyl azides. ${ }^{9}$ Treatment of aldehyde $\mathbf{5 . 3}$ with vinyl-magnesium chloride results in alkoxide $\mathbf{5 . 4}$, which can be trapped in situ with DPPA. 
After displacement with azide, the conjugated isomer $\mathbf{5 . 5}$ was the sole observed product. There have been reports utilizing the single conjugated isomer synthetically. ${ }^{10,11}$
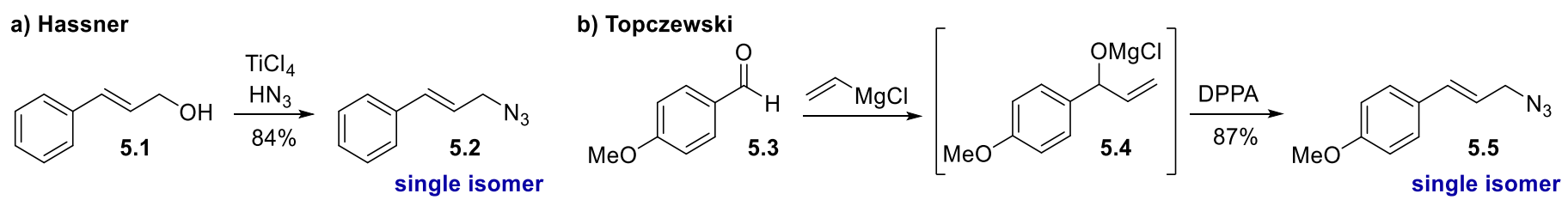

Scheme 5. Effects of conjugation to arene on equilibrium.

Conjugation greatly shifts the equilibrium ratio towards the conjugated azide isomer. While the isomer distribution is governed by thermodynamic considerations, there is evidence that the Winstein rearrangement is still kinetically accessible. For example, cis-cinnamyl azide was irreversibly converted to trans-cinnamyl azide upon mild heating (Scheme 6a). ${ }^{12}$ This isomerization was proposed to occur via two [3,3] sigmatropic rearrangements, first uphill to the unconjugated isomer, and then back to the most stable trans-isomer. Upon standing, azide 6.3 partially isomerized to the (Z)-isomer (Scheme 6b). ${ }^{13}$ Noticing this isomerization, the equilibrium ratio was measured at $75{ }^{\circ} \mathrm{C}$ in benzene. At equilibrium a 3.2:1 mixture of $E$ and $Z$ isomers was observed (Scheme 6b). Density functional theory (DFT) calculations describe a three-step pathway consisting of a [3,3] rearrangement, $\sigma$-bond rotation, and a second [3,3] rearrangement (vide infra)..$^{13}$ These examples highlight that while the unconjugated isomer is not directly observed, it is likely an intermediate in the observed isomerization.

a) Banert

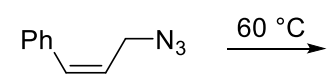

6.1

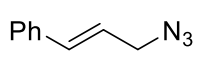

6.2 b) Topczewski

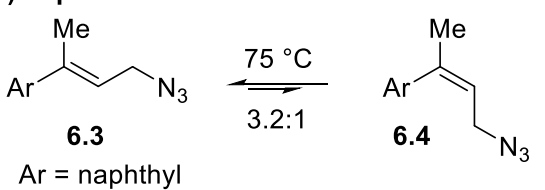

Scheme 6. $E / Z$ Isomerization of conjugated allylic azides.

Other reports showed that conjugation to an electron-withdrawing group results in predominantly a single azide isomer. In an example from Panek and co-workers, an allylic azide was generated from a Lewis acid catalyzed addition to an acetal (Scheme 7a). ${ }^{14}$ Investigations of this reaction revealed that the crude reaction mixture was a 3:1 mixture of $\alpha$-azido ester 7.2 and the rearranged conjugated product 7.3. After work-up and purification by column chromatography, only the conjugated product (7.3) was isolated. In a similar observation, Evans and co-workers reported a single isomer upon displacement of an activated allylic alcohol with sodium azide (Scheme $7 b)^{15}$. Both of these examples indicate that conjugation to an electron withdrawing group is sufficient to bias the Winstein rearrangement.

a) Panek

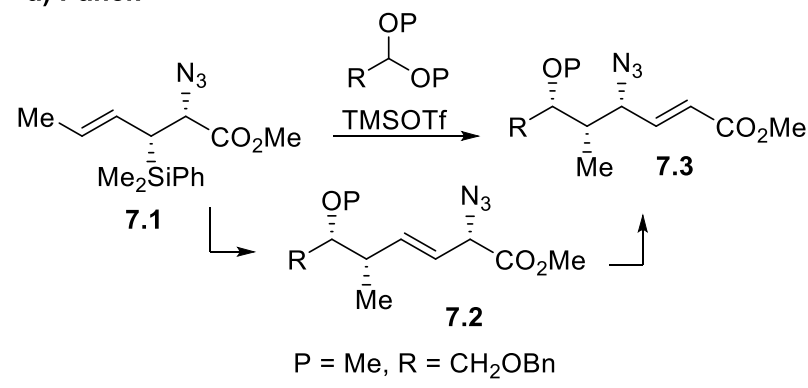

b) Evans

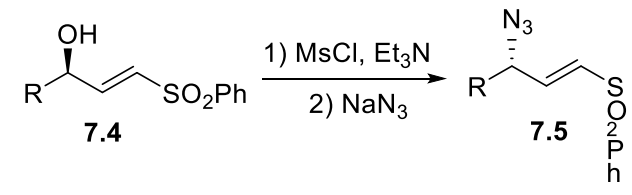

Scheme 7. Conjugation to electron-withdrawing group. 
A measurable equilibrium can be re-established if both allylic termini are substituted with a conjugating group (Scheme 8). ${ }^{13}$ In the cases examined, there was a slight preference for conjugation to the ester over the arene (Scheme 8a). Changing the electronics of the arene had little effect on the equilibrium (Scheme 8a vs $8 b)$. Interestingly, when the ester was replaced with a nitrile, only the isomer conjugated to the nitrile was observed as a mixture of $E$ and $Z$ isomers (Scheme $8 d$ ).

a)

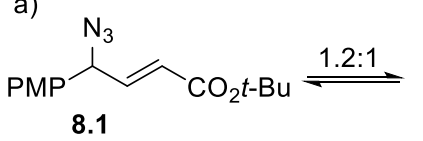

b) $\mathrm{N}_{3}$

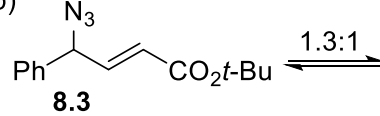

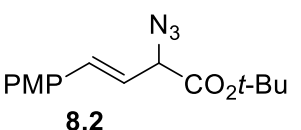

8.2

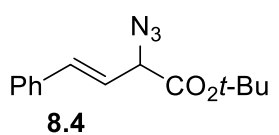

c)

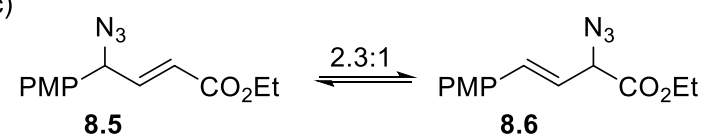

d)

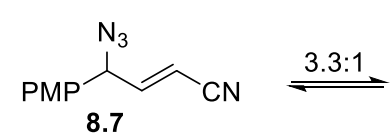

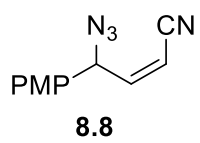

PMP = para-methoxyphenyl

Scheme 8. Conjugation to both Isomers.

Spino reported the equilibrium of an allylic azide with a diene motif (Scheme 9). ${ }^{16}$ Mitsunobu conditions were used to generate an allylic azide from dienol 9.1. There are three possible regioisomers of the resulting azide. The azide can be proximal to the menthol derivative (azide 9.2), distal to the menthol derivative (azide 9.4), or the azide can be in between the two alkenes (azide 9.3). Only azide $\mathbf{9 . 4}$ was observed. Azide $\mathbf{9 . 3}$ is likely disfavored due to lack of conjugation and azide $\mathbf{9 . 2}$ is disfavored due to steric considerations (vide infra).
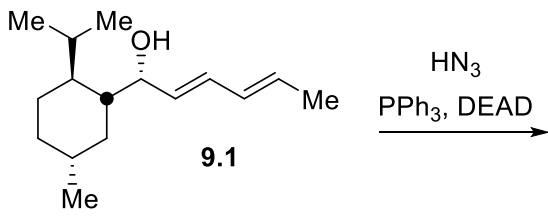
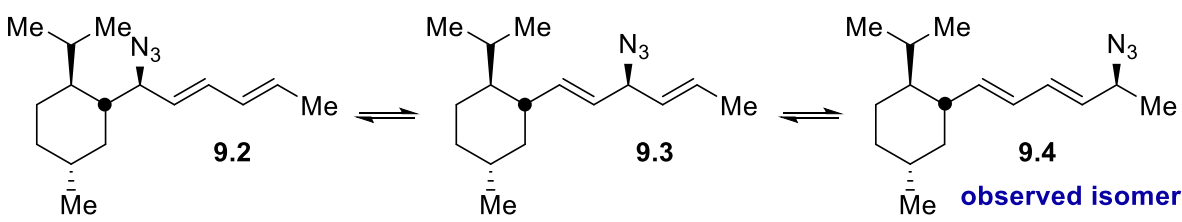

Scheme 9. Conjugation to an alkene.

\subsection{Steric effects: syn-pentane interactions}

Similar to the effect of conjugation, conformational and steric effects can greatly bias the equilibrium ratio in favor of one isomer. Spino strategically utilized a menthol derivative to synthesize $\alpha$-amino acids and heterocycles using an allylic azide intermediate. ${ }^{17}$ The menthol derivative acted as a chiral auxiliary to set the stereocenter of the allylic alcohol. The auxiliary was also a critical factor in establishing the equilibrium ratio of azide isomers after the Mitsunobu reaction (Scheme 10). Mitsunobu reactions are known to result in predominantly $S_{N} 2$ over $S_{N} 2^{\prime}$ products. ${ }^{18,19}$ Therefore, Spino proposed initial $S_{N} 2$ displacement of the activated alcohol with azide to generate allylic azide $\mathbf{1 0 . 2}$. Azide $\mathbf{1 0 . 2}$ is destabilized due to a syn-pentane interaction with the isopropyl group from the menthol moiety. The rearranged product $\mathbf{1 0 . 3}$ avoids these steric interactions and is the predominant isomer observed when $R$ is alkyl (>98:2). It is noteworthy that when $R$ is $\mathrm{Ph}$, the selectivity of the products is reversed and $\mathbf{1 0 . 2}$ is formed (94:6). Conjugation of the alkene to the aryl ring outweighs the syn-pentane interaction between the azide and isopropyl group. 


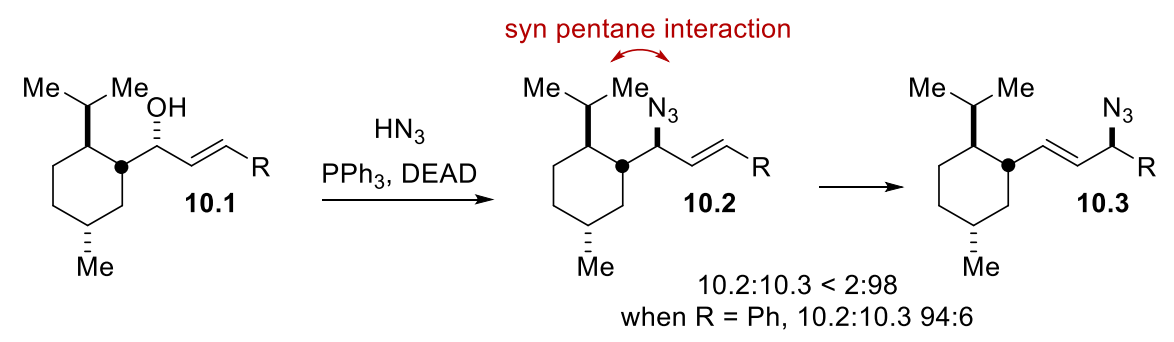

Scheme 10. Effect of syn-pentane Interactions on equilibrium.

We noticed the effect of syn-pentane interactions when working with complex allylic azide substrates (Scheme 11). ${ }^{20}$ These substrates were used for a dynamic cyclization reaction specifically from the tertiary azide isomer. Typical substrates contained a measurable mixture of secondary and tertiary azides (Scheme 11a). The secondary azide was present as a mixture of alkene isomers. Only the secondary azide was observed for a similar substrate bearing a geminal dimethyl group (Scheme 11b). This is likely due to a syn-pentane interaction destabilizing the tertiary azide isomer (11.5) relative to the others. Interestingly, the trace concentration of this isomer was able to undergo the desired cyclization reaction in good yield, illustrating the Curtin-Hammett principle.

a)

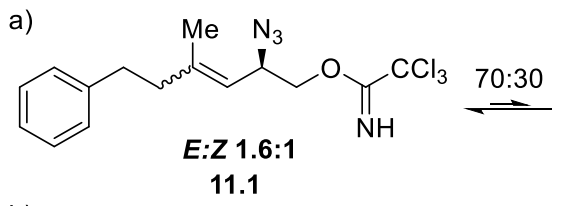

b)

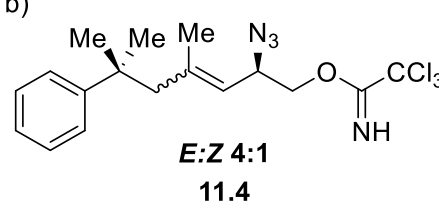

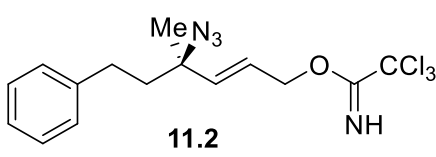

11.2

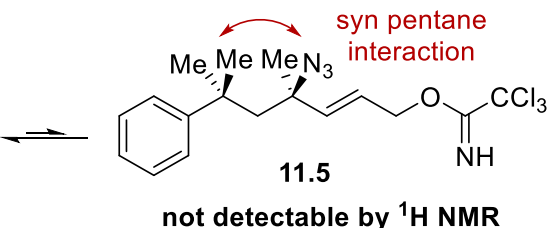

not detectable by ${ }^{1} \mathrm{H}$ NMR
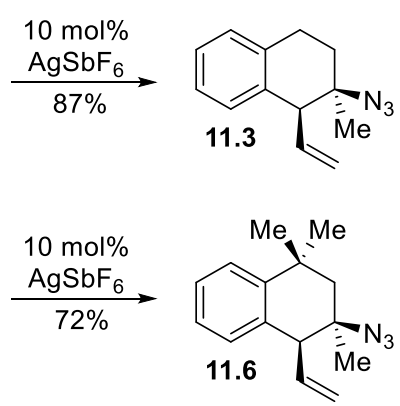

Scheme 11. Syn-pentane interaction affects equilibrium.

\subsection{Stereoelectronic effects}

Sharpless noted that the equilibrium of prenyl and crotyl azides was affected by the incorporation of an oxygen atom on one end of the allylic system (Scheme 12). While prenyl and crotyl azide favored the primary azide by more than two fold, adding a hydroxyl group shifted the equilibrium to roughly 1:1. ${ }^{21} \mathrm{~A}$ hydrogen bond between the azide and pendant hydroxyl group was proposed to be responsible for this effect. Topczewski and co-workers probed further whether this effect was solely due to a hydrogen bond or if there was also an electronic parameter. ${ }^{22}$

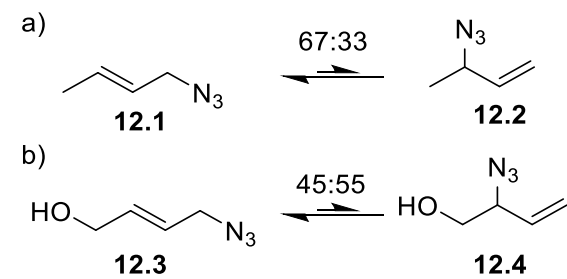

c)

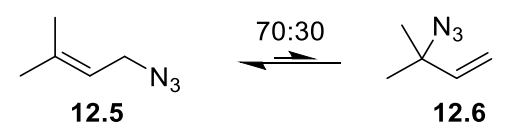

d)<smiles>CC(=CC#N)CO</smiles>

12.7

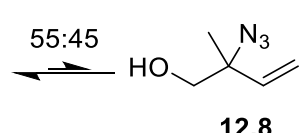

Scheme 12. Effect of heteroatom on equilibirum. 
A series of allylic ethers were synthesized and the equilibrium ratio of linear to branched azide was measured (Scheme 13, I:b). In this case, the equilibrium ratio was dependent on the electronic nature of the group bound to oxygen. Substituents with more electron-donating groups on the oxygen led to an increase in the percentage of the branched azide at equilibrium (Scheme 13). The percent branched isomer correlated with the DMSO pKa of the OR group's conjugate acid. The heteroatom may either be stabilizing the branched isomer or destabilizing the linear isomer. Based on DFT calculations, the heteroatom likely increased stabilization of the branched isomer via the gauche effect. These results indicate that the exact equilibrium ratio can be dependent on proximal groups.

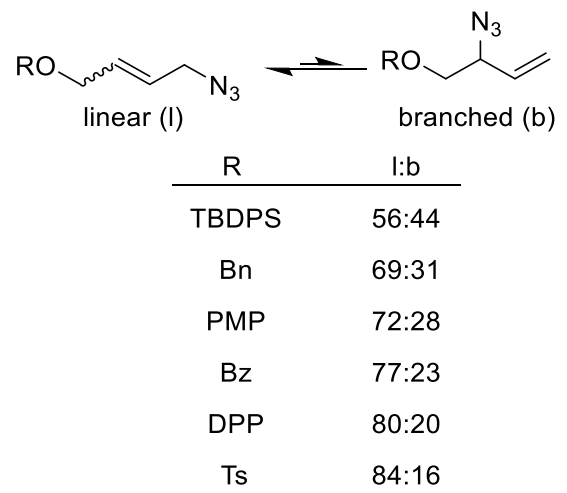

Scheme 13. Effect of OR group on equilibrium.

In a related study, Göksu and co-workers synthesized a series of cyclic bis-azides (Scheme 14). ${ }^{23}$ The cyclic bis-azides were accessed by a Mitsunobu reaction originating from either a meso-diol (14.1) or from an epoxide (14.4), through ring opening and subsequent Mitsunobu reaction. Depending on the precursor, a different allylic azide was accessed as the kinetic product of the reaction. The authors noted that for azides with $n=2$ or 3 , a mixture with a varying ratio was obtained from either precursor. With $n=1$ or 4 , only one azide was isolated. When $n=4$, either isomer could be obtained, depending on the starting material. This indicates that the rearrangement is slow for the cyclooctenyl system. The equilibrium constant in this case was not determined. A computational analysis supported a [3,3] sigmatropic process.

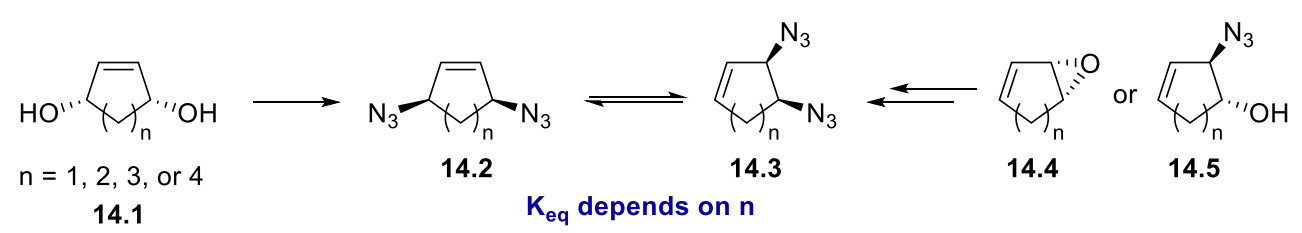

Scheme 14. Effect of ring size on equilibrium.

Conjugation, syn-pentane interactions, and stereoelectronic effects play a key role in the equilibrium of allylic azide isomers. Effects, which lead to predominately one isomer, can provide a means to further elaborate some allylic azides. For example, Trost and Pully utilized the shift in equilibrium caused by a pendant hydroxy group for the synthesis of (+)-Conduramine E. ${ }^{24}$ In cases where the equilibrium constant is near unity, it is more challenging to utilize these substrates because selective downstream reactions are required. While challenging, successful examples do exist. ${ }^{20,25,26}$ 


\section{Mechanistic Insights}

\subsection{Evidence for stereospecificity}

Padwa and co-workers were first to report the stereospecificity of the Winstein rearrangement (Scheme 15). A stereodefined $\alpha$-diazo- $\gamma$-azido- $\delta$-hydroxy ketoester was exposed to a rhodium catalyst, which resulted in an 0 $\mathrm{H}$ insertion reaciton. ${ }^{27}$ While similar substrates without an azide resulted in a mixture of diastereomers, azide $\mathbf{1 5 . 1}$ resulted in a single diastereomer. This process likely proceeds via (i) initial formation of ketoester $\mathbf{1 5 . 2}$ followed by (ii) tautomerization to the enol. This results in allylic azide 15.3, which can (iii) rearrange to generate the enol 15.4. The last step (iv) is the tautomerization to ketone 15.5. Because the stereochemistry of the initial substrate dictates the stereochemistry of the product, it was concluded that this process proceeds with stereospecificity. The stereospecificity of this reaction supports the previously proposed [3,3] sigmatropic mechanism.

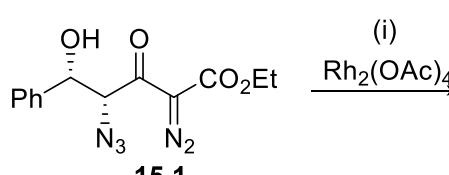

15.1

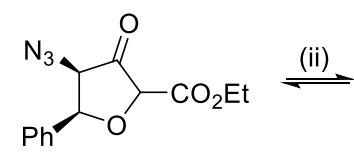

15.2

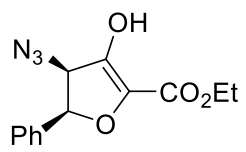

15.3

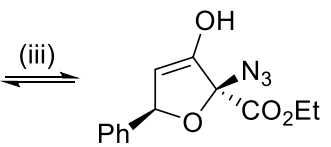

15.4

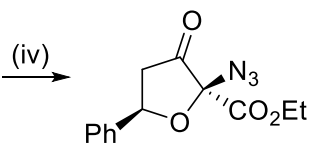

15.5

Scheme 15. Stereospecific winstein rearrangement.

There are other examples that highlight the stereospecificity of the allylic azide rearrangement. The Blechert group was interested in using azides to access glycosyl phosphate surrogates (Scheme 16). ${ }^{11}$ Using an enzymatic resolution, alcohol $\mathbf{1 6 . 1}$ was converted to allylic acetate $\mathbf{1 6 . 2}$, which was isolated in high enantiopurity. A palladium-catalyzed allylic substitution converted the acetate to the corresponding azide with retention of stereochemistry. While this azide exists primarily as a single isomer due to conjugation, the Winstein rearrangement is still kinetically viable (vide supra). The lack of observed enantioerosion of azide $\mathbf{1 6 . 3}$ is consistent with a [3,3] sigmatropic mechanism.
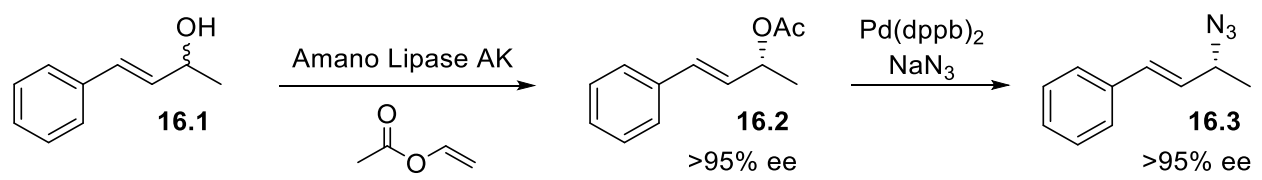

Scheme 16. Azide rearrangement is stereospecific.

\subsection{Computational investigations}

Several groups have studied the allylic azide rearrangement using DFT calculations. Jabbari found energy profiles for the rearrangement of a few simple azides (Scheme 17). ${ }^{28}$ The transition state energy was slightly lower for the hydroxylated substrate 17.3. The author proposed that a hydrogen bond stabilizes the transition state; however, based on other work, there are likely other electronic effects (vide supra). ${ }^{22}$ In a similar report, the Kang group used DFT to study the allylic azide rearrangement of pimarily prenyl and crotyl azide along with the corresponding hydroxyl deriviatives. ${ }^{29}$ From the energy profiles, the equilibrium ratio of isomers was estimated and was found to be consistent with experimental values. Labadie and coworkers conducted a similar study with a primary focus on prenyl azides of various chain lengths. ${ }^{30}$ Modifying the chain length, temperature, or solvent did not significantly change the equilibrium constant, which is consistent with 
Winstein's initial report. All three groups concluded that the rearrangement is a concerted synchronous process. A half-chair geometry was calculated for the transition state structure. ${ }^{28-30}$
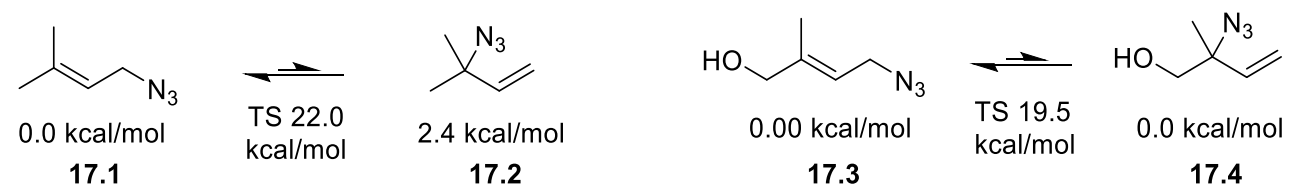

Scheme 17. Free energy profiles of allylic azide rearrangement.

The Topczewski group became interested in studying the allylic azide rearrangement using DFT calculations after observing the $E$ to $Z$ isomerization of azide 18.1. ${ }^{13}$ Presumably, the isomerization occurs via the Winstein rearrangement and DFT was used to identify a pathway for isomerization. The calculations describe a three step process: (i) a [3,3] sigmatropic rearrangement to benzylic azide $\mathbf{1 8 . 2}$, (ii) $\sigma$-bond rotation, and (iii) a second sigmatropic rearrangement.
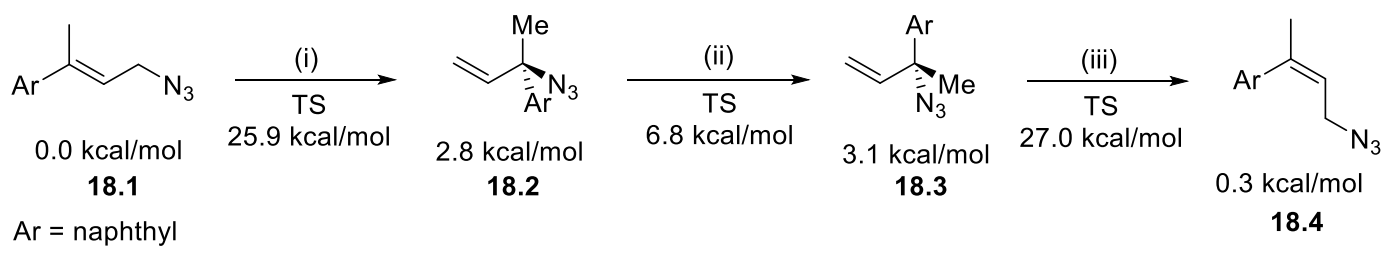

Scheme 18. Pathway for $E$ to $Z$ isomerization.

With a pathway identified, the rate of isomerization and the stereochemical outcome of an analogous rearrangement could be investigated (Scheme 19). The rate constants for isomerization of azides 19.1 and 19.3 were measured in benzene at $75^{\circ} \mathrm{C}$. The rate constants for equilibration were $7.1 \times 10^{-4} \mathrm{~s}^{-1}$ for azide 19.1 and $5.0 \times 10^{-3} \mathrm{~s}^{-1}$ for azide 19.3. ${ }^{13}$ The small structural difference (added methyl in azide 19.3) resulted in a significant rate enhancement. This observation is consistent with Winstein's observation that prenyl azide rearranged faster than crotyl azide under all conditions investigated. ${ }^{4}$ The added methyl group plays a role in increasing the rate of rearrangement, likely due to the increased electron density of the alkene. If one considers the observed rates of rearrangement for prenyl azide (Scheme 2), one could conclude that the aryl further enhances the rate of rearrangement. The rearrangement of enantioenriched azide 19.3 occurred with formal inversion of the stereocenter but without loss of stereochemical integrity.

a)

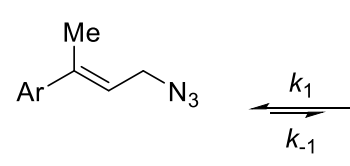

19.1

$$
\begin{gathered}
\left(k_{1}+k_{-1}\right)=7.1 \times 10^{-4} \mathrm{~s}^{-1} \\
\text { At } 75^{\circ} \mathrm{C} \text { in } \mathrm{C}_{6} \mathrm{D}_{6} \\
\text { Ar }=\text { naphthyl }
\end{gathered}
$$

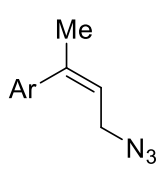

19.2

Scheme 19. E to Z Equilibration.

b)

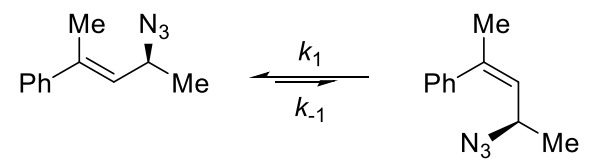

19.3, $>99: 1$ er

19.4, >99:1 er

$$
\begin{gathered}
\left(k_{1}+k_{-1}\right)=5.0 \times 10^{-3} \mathrm{~s}^{-1} \\
\text { At } 75^{\circ} \mathrm{C} \text { in } \mathrm{C}_{6} \mathrm{D}_{6}
\end{gathered}
$$




\section{3 ${ }^{15} \mathrm{~N}$ Labelling study}

Topczewski and co-workers undertook an ${ }^{15} \mathrm{~N}$ labelling study to provide direct evidence for the [3,3] sigmatropic mechanism (Scheme 20). ${ }^{13}$ The ${ }^{15} \mathrm{~N}$ label was installed from ${ }^{15} \mathrm{~N}$-phthalimide using an iridium catalyzed allylic substitution reaction. Deprotection using ethanolamine yielded labelled amine 20.3. Diazo transfer with triflic azide, formed in situ, resulted in branched azide 20.4. Rearrangement to cinnamyl azide was concomitant. A [1,3] sigmatropic, [3,3] sigmatropic, or ionic mechanism would result in different positions of the ${ }^{15} \mathrm{~N}$ label. If the azide rearrangement proceeded via a [1,3] sigmatropic mechanism, the ${ }^{15} \mathrm{~N}$ label would be located on the proximal nitrogen (azide 20.5), while a [3,3] rearrangement would shift the ${ }^{15} \mathrm{~N}$ label to the distal nitrogen atom (azide 20.6). An ionic mechanism would result in scrambling of the ${ }^{15} \mathrm{~N}$ label. The cinnamyl azide was reduced and analyzed by HRMS, which revealed that the ${ }^{15} \mathrm{~N}$ label was no longer present. The absence of the ${ }^{15} \mathrm{~N}$ label in the reduced product provides direct evidence for the [3,3] sigmatropic mechanism.

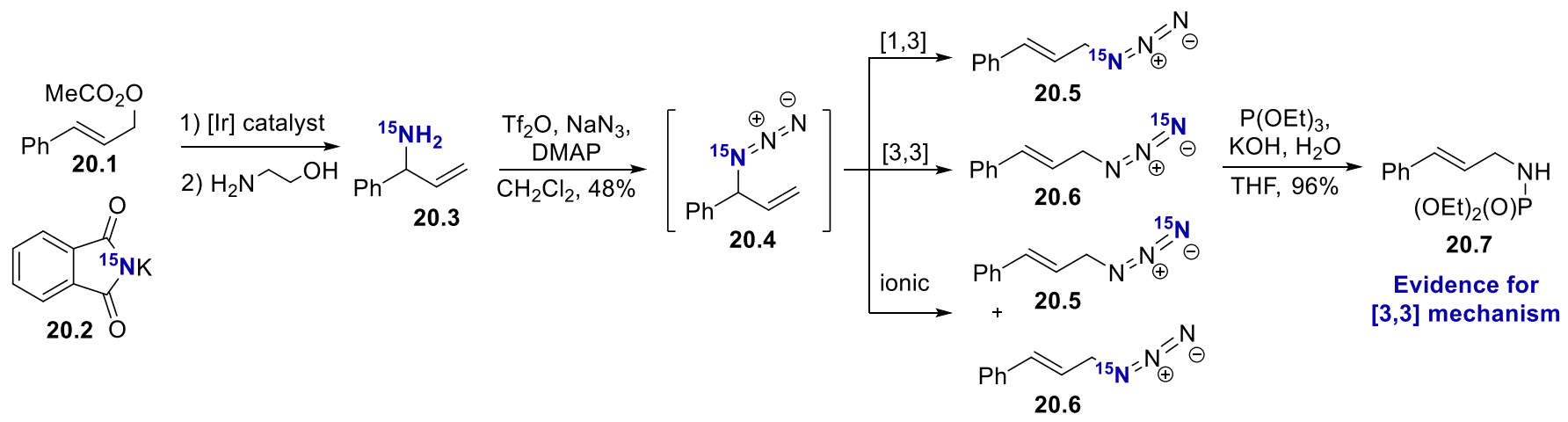

Scheme $20 .{ }^{15} \mathrm{~N}$-Labelled allylic azide rearrangement.

\subsection{Ionic and catalyzed pathways for the Winstein rearrangement}

Based on the above discussion, it is generally accepted that the Winstein rearrangement proceeds by a [3,3] sigmatropic mechanism. However, an ionic mechanism can be accessed under certain conditions. Products corresponding to an ionic mechanism were observed upon heating enantioenriched cyclic allylic azides (Scheme 21). ${ }^{13}$ These azides were designed because they exist as the conjugated isomer and do not racemize by a [3,3] mechanism. They were found to be stable in less polar solvents for over one week at $100{ }^{\circ} \mathrm{C}$. In contrast, these azides quickly racemized and formed products of methanolysis in $\mathrm{MeOH}$ at $100{ }^{\circ} \mathrm{C}$. This observation along with a strong rate correlation to the Hammett value $\sigma^{+}$indicated an ionic mechanism.

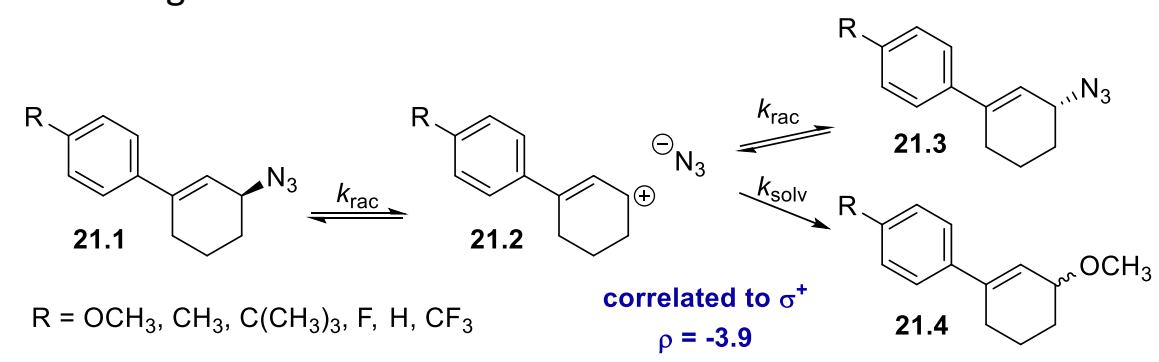

Scheme 21. Ionic mechanism for winstein rearrangment.

Others documented azide racemization in the presence of a catalyst. In 2017, Toste and coworkers reported partial racemization of an allylic azide, which could not be explained by a [3,3] mechanism. Chiral 
allylic azides were accessed from a gold-catalyzed allene functionalization reaction. ${ }^{31} \mathrm{~A}$ control experiment was conducted to determine whether the reaction conditions led to racemization of the azide product. A mixture of the enantioenriched allylic azide and in situ generated cationic gold complex resulted in a significant decrease in ee in chloroform (Scheme 22). Some enantioerosion was observed in toluene, and minimal enantioerosion was observed in THF. While not described at the time, a catalyzed ionic mechanism likely led to partial racemization (vide infra). The ionic mechanism is probably inhibited by the coordination of THF to the catalyst or slowed down due to reduced solvent polarity (PhMe).

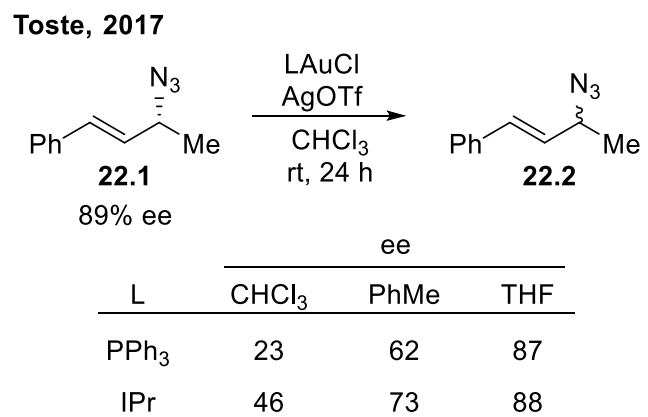

Scheme 22. Racemization of allylic azides.

The Aubé lab selectively trapped an isomer from the allylic azide rearrangement. They developed an intramolecular Schmidt reaction promoted by Lewis acid to generate substituted lactams (Scheme 23). ${ }^{26}$ Because the rearrangement is stereospecific, they envisioned using a stereodefined starting material to generate stereodefined products. However, while investigating this process, Liu noticed that the syn:anti ratio did not smoothly translate to the products (Scheme 23a). ${ }^{32}$ With this substrate, it was unclear which stereocenter was being epimerized because the ketone could isomerize via an enol/enolate. Further investigations were conducted using an alternate substrate (Scheme 23b). This substrate was designed to avoid potential epimerization at any other stereocenters and resulted in only one regioisomer. Again, there was a clear change in the ratio of diastereomers after treatment with $\mathrm{SnCl}_{4}$ (Scheme 23b). These strongly Lewis acidic conditions were likely able to promote an ionic mechanism, causing a distinct change in the diastereomeric ratio.

a)

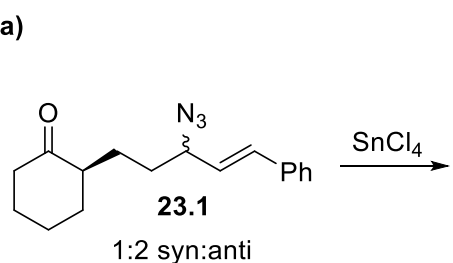

$1: 2$ syn:anti

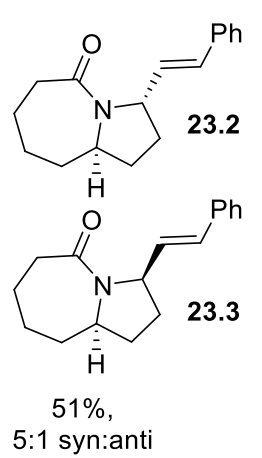

b)
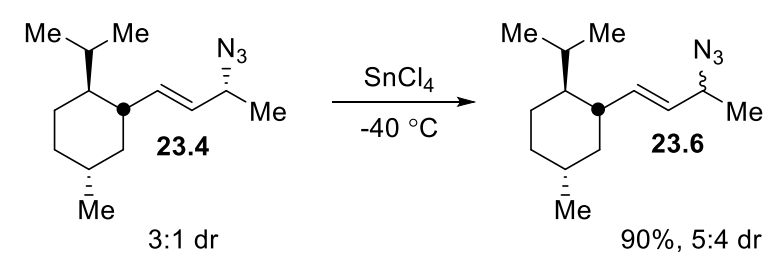

Scheme 23. Unexpected selectivity.

The Topczewski lab became interested in identifying mild conditions that lead to facile racemization of allylic azides. ${ }^{33}$ Several suitable catalysts were able to promote this process. Selected examples highlight the ability to tune the catalyst based on the substrate (Table 1). A mechanistic study revealed that the 
racemization is strongly correlated to the Hammett parameter $\sigma^{+}$, indicating a buildup of positive charge in the transition state. The highly negative slope $(\rho=-5.9)$ is indicative of a carbenium intermediate. Other substrates with carbenium stabilizing groups could be racemized under these conditions, expanding catalytic racemization beyond allylic azides.

Table 1. Racemization of activated azides

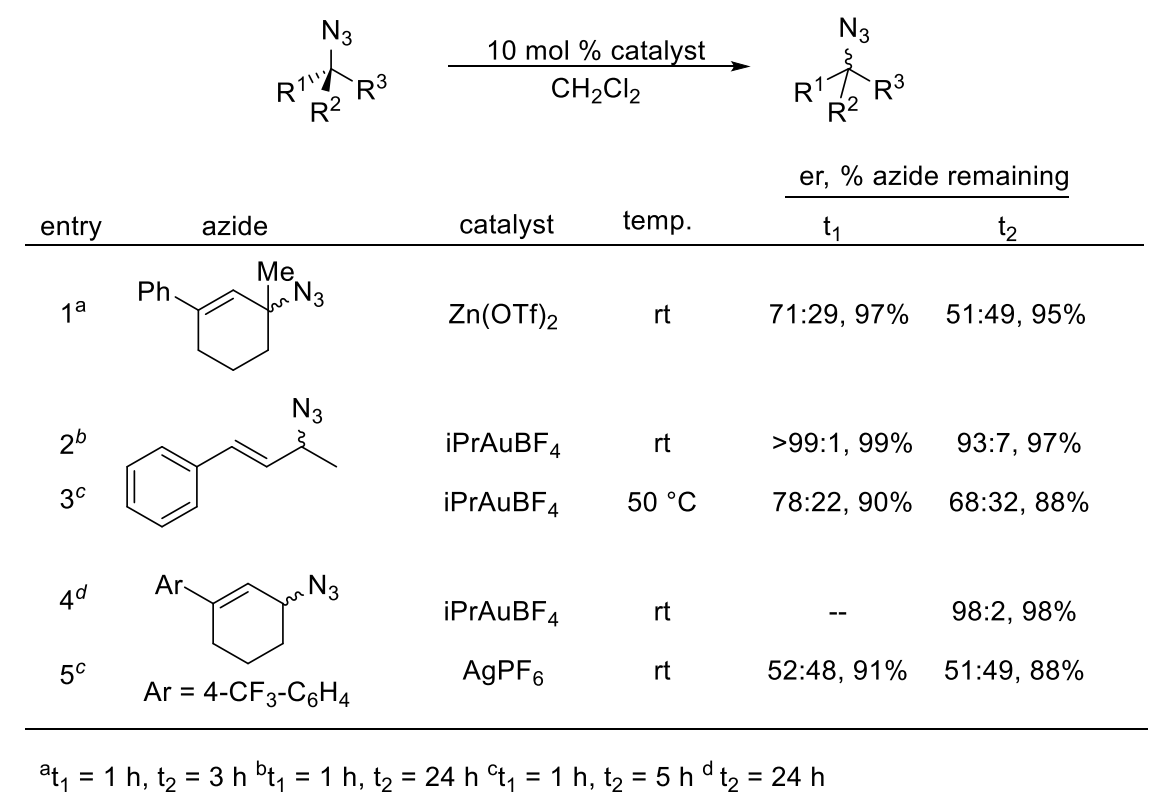

\section{Conclusions}

Since Winstein's initial report on the spontaneous rearrangement of allylic azides, there have been scattered reports providing insights into the characteristics of this process. As with all equilibria, this rearrangement is governed by the difference in energy between the possible azide isomers. A number of factors have been identified that effect the equilibrium ratio including alkene substitution, conjugation, conformational effects, and stereoelectronics. In some cases, the minor isomers cannot be directly observed. The mechanism of the rearrangement is a stereospecific [3,3] sigmatropic process in most cases. This is supported by various experimental techniques and computational studies. However, the rearrangement can proceed via an ionic pathway under certain conditions that proceeds with loss of stereochemical information. To utilize allylic azides in synthesis, either a biased equilibrium or a selective functionalization is required. Several groups have put forth efforts to develop methods for the selective functionalization of a single allylic azide isomer. ${ }^{20,21,34-37}$

\section{Acknowledgements}

Financial support was provided by the University of Minnesota and The American Chemical Society's Petroleum Research Fund (PRF \# 56505-DNI1). This research was supported by the National Institute of General Medical Sciences of the National Institutes of Health under Award Number R35GM124718. 


\section{References}

1. Bräse, S.; Gil, C.; Knepper, K.; Zimmermann, V. Organic Azides: An Exploding Diversity of a Unique Class of Compounds. Angew. Chem. Int. Ed. 2005, 44, 5188-5240.

https://doi.org/10.1002/anie.200400657

2. Brase, S.; Banert, K. Organic Azides: Synthesis and Applications; John Wiley and Sons: Chichester, 2010.

3. Scriven, E. F. V; Turnbull, K. Azides: Their Preparation and Synthetic Uses. Chem. Rev. 1988, 88, $297-368$. https://doi.org/10.1021/cr00084a001

4. Gagneux, A.; Winstein, S.; Young, W. G. Rearrangement of Allyl Azides. J. Am. Chem. Soc. 1960, 82, 59565957.

https://doi.org/10.1021/ja01507a045

5. Le Noble, W. J. The Effect of Pressure on the Equilibration of $\alpha$ - and $\gamma$-Methylallyl Azide. J. Phys. Chem. 1963, 67, 2451-2453.

https://doi.org/10.1021/j100805a047

6. VanderWerf, C. A.; Heisler, R. V; McEwen, W. E. The Reaction of Sodium Azide with Some Representative Epoxides. J. Am. Chem. Soc. 1954, 76, 1231-1235.

https://doi.org/10.1021/ja01634a008

7. Vollhardt, P.; Schore, N. Organic Chemistry Structure and Function, 8th ed.; W. H. Freeman and Company: New York, 2018.

8. Hassner, A.; Fibiger, R.; Andisik, D. Lewis Acid Catalyzed Conversion of Alkenes and Alcohols to Azides. J. Org. Chem. 1984, 49, 4237-4244.

https://doi.org/10.1021/jo00196a025

9. Goswami, P. P.; Suding, V. P.; Carlson, A. S.; Topczewski, J. J. Direct Conversion of Aldehydes and Ketones into Azides by Sequential Nucleophilic Addition and Substitution. Eur. J. Org. Chem. 2016, 4805-4809. https://doi.org/10.1002/ejoc.201600856

10. Carlson, A. S.; Calcanas, C.; Brunner, R. M.; Topczewski, J. J. Regiocontrolled Wacker Oxidation of Cinnamyl Azides. Org. Lett. 2018, 20, 1604-1607.

https://doi.org/10.1021/acs.orglett.8b00344

11. Schuster, M.; He, W. F.; Blechert, S. Chemical-Enzymatic Synthesis of Azasugar Phosphonic Acids as Glycosyl Phosphate Surrogates. Tetrahedron Lett. 2001, 42, 2289-2291.

https://doi.org/10.1016/S0040-4039(01)00137-X

12. Banert, K.; Hagedorn, M.; Liedtke, C.; Melzer, A.; Schöffler, C. Reactions of Unsaturated Azides, 12 Azido1,2,3-Triphenylpropenes of Varying Stabilities: A Corrigendum of Structure Assignment. Eur. J. Org. Chem. 2000, 257-267.

https://doi.org/10.1002/(SICI)1099-0690(200001)2000:2<257::AID-EJOC257>3.0.CO;2-R

13. Ott, A. A.; Packard, M. H.; Ortuño, M. A.; Johnson, A.; Suding, V. P.; Cramer, C. J.; Topczewski, J. J. Evidence for a Sigmatropic and an Ionic Pathway in the Winstein Rearrangement. J. Org. Chem. 2018, 83, 8214-8224.

https://doi.org/10.1021/acs.joc.8b00961

14. Panek, J.; Yang, M.; Muler, I. Sequential Diastereoselective Addition and Allylic Azide Isomerization of Syn- and Anti- $\alpha$-Azido- $\beta$-(Dimethylphenylsilyl)-(E)-Hex-4-Enoates with Acetals: Asymmetric Synthesis of ${ }^{-}$Hydroxy- $\alpha$-Amino Acid Synthons. J. Org. Chem. 1992, 54, 4063-4064.

https://doi.org/10.1021/jo00041a002

15. Evans, D. A.; Andrews, G. C. Allylic Sulfoxides: Useful Intermediates in Organic Synthesis. Acc. Chem. Res. 
1974, 7, 147-155.

https://doi.org/10.1021/ar50077a004

16. Lauzon, S.; Tremblay, F.; Gagnon, D.; Godbout, C.; Chabot, C.; Mercier-Shanks, C.; Perreault, S.; DeSeve, H.; Spino, C. Sterically Biased 3,3-Sigmatropic Rearrangement of Chiral Allylic Azides: Application to the Total Syntheses of Alkaloids. J. Org. Chem. 2008, 73, 6239-6250.

https://doi.org/10.1021/jo800817p

17. Gagnon, D.; Lauzon, S.; Godbout, C.; Spino, C. Sterically Biased 3,3-Sigmatropic Rearrangement of Azides: Efficient Preparation of Nonracemic $\alpha$-Amino Acids and Heterocycles. Org. Lett. 2005, 7, 4769-4771. https://doi.org/10.1021/ol052034n

18. Mitsunobu, O. The Use of Diethyl Azodicarboxylate and Triphenylphosphine in Synthesis and Transformation of Natural Products. Synthesis 1981, 1, 1-28.

https://doi.org/10.1055/s-1981-29317

19. Trost, B. M.; Kondo, Y. An Symmetric Synthesis of (+)-Phyllanthocin. Tetrahedron Lett. 1991, 32, 16131616.

\section{https://doi.org/10.1016/S0040-4039(00)74285-7}

20. Porter, M. R.; Shaker, R. M.; Calcanas, C.; Topczewski, J. J. Stereoselective Dynamic Cyclization of Allylic Azides : Synthesis of Tetralins, Chromanes, and Tetrahydroquinolines. J. Am. Chem. Soc. 2018, 140, 1211-1214.

https://doi.org/10.1021/jacs.7b11299

21. Feldman, A. K.; Colasson, B.; Sharpless, K. B.; Fokin, V. V. The Allylic Azide Rearrangement: Achieving Selectivity. J. Am. Chem. Soc. 2005, 127, 13444-13445.

https://doi.org/10.1021/ja050622q

22. Packard, M. H.; Cox, J. H.; Suding, V. P.; Topczewski, J. J. The Effect of Proximal Functionality on the Allylic Azide Equilibrium. Eur. J. Org. Chem. 2017, 6365-6368.

https://doi.org/10.1002/ejoc.201700693

23. Góksu, S.; Ozalp, C.; Seçen, H.; Sütbeyaz, Y.; Saripinar, E. Double Mitsunobu Reactions of Cis-Cycloalk-2Ene-1,4-Diols and 3,4-Epoxycycloalkenes: Rearrangements of Allylic Diazides. Synthesis 2004, 2849-2854. https://doi.org/10.1055/s-2004-831258

24. Trost, B. M.; Pulley, S. R. On the Flexibility of Allylic Azides as Synthetic Intermediates. Tetrahedron Lett. 1995, 36, 8737-8740. https://doi.org/10.1016/0040-4039(95)01898-R

25. Vekariya, R. H.; Liu, R.; Aubé, J. A Concomitant Allylic Azide Rearrangement/Intramolecular Azide-Alkyne Cycloaddition Sequence. Org. Lett. 2014, 16, 1844-1847.

https://doi.org/10.1021/ol500011f

26. Liu, R.; Gutierrez, O.; Tantillo, D. J.; Aubé, J. Stereocontrol in a Combined Allylic Azide Rearrangement and Intramolecular Schmidt Reaction. J. Am. Chem. Soc. 2012, 134, 6528-6531.

https://doi.org/10.1021/ja300369c

27. Padwa, A.; Sa, M. M. Intramolecular O-H Insertion Reaction of Azido Substituted Diazoesters and Its Relevance to the Mechanism of the Ailylic Azide Rearrangement. Tetrahedron Lett. 1997, 38, 5087-5090. https://doi.org/10.1016/S0040-4039(97)01133-7

28. Jabbari, A. Transition States and Activation Barriers for [3,3]-Sigmatropic Shift of Allyl Azides. Org. Chem. J. 2010, 1, 6-14.

29. Kang, H.; Kang, Y. K. Allylic Azide Rearrangements Investigated by Density Functional Theory Calculations. Bull. Korean Chem. Soc. 2017, 38, 1419-1426. 


\section{https://doi.org/10.1002/bkcs.11318}

30. Porta, E. O. J.; Vallejos, M. M.; Bracca, A. B. J.; Labadie, G. R. Experimental and Theoretical Studies of the [3,3]- Sigmatropic Rearrangement of Prenyl Azides. RSC Adv. 2017, 7, 47527-47538.

\section{https://doi.org/10.1039/c7ra09759j}

31. Khrakovsky, D. A.; Tao, C.; Johnson, M. W.; Thornbury, R. T.; Shevick, S. L.; Toste, F. D. Enantioselective, Stereodivergent Hydroazidation and Hydroamination of Allenes Catalyzed by Acyclic Diaminocarbene (ADC) Gold (I) Complexes. Angew. Chem. Int. Ed. 2016, 91125, 6079-6083.

\section{https://doi.org/10.1002/anie.201601550}

32. Liu, R. A Combined Allylic Azide Rearrangement and Intramolecular Schmidt Reaction - Discovery, Development, And Application. Ph.D Diss. Univ. Kansas 2003.

33. Ott, A. A.; Topczewski, J. J. Catalytic Racemization of Activated Organic Azides. Org. Lett. 2018, 20, 72537256.

\section{https://doi.org/10.1021/acs.orglett.8b03168}

34. Ott, A. A.; Goshey, C. S.; Topczewski, J. J. Dynamic Kinetic Resolution of Allylic Azides via Asymmetric Dihydroxylation. J. Am. Chem. Soc. 2017, 139, 7737-7740.

https://doi.org/10.1021/jacs.7b04203

35. Moynihan, L.; Chadda, R.; Mcardle, P.; Murphy, P. V. Allylic Azide Rearrangement in Tandem with Huisgen Cycloaddition for Stereoselective Annulation: Synthesis of C-Glycosyl Iminosugars. Org. Lett. 2015, 17, 6226-6229. https://doi.org/10.1021/acs.orglett.5b03209

36. Craig, D.; Harvey, J. W.; O’Brien, A. G.; White, A. J. P. Claisen Rearrangements of Equilibrating Allylic Azides. Org. Biomol. Chem. 2011, 9, 7057-7061.

https://doi.org/10.1039/c1ob05972f

37. Chadda, R.; Mcardle, P.; Murphy, P. V. Allylic Azide Rearrangement in Tandem with Intramolecular Huisgen Cycloaddition for Iminosugar and Glycomimetic Synthesis: Functionalized Piperidine, Pyrrolidine, and Pyrrolotriazoles from D-Mannose. Synthesis 2017, 49, 2138-2152.

https://doi.org/10.4125/pd0092th

\section{Authors' Biographies}

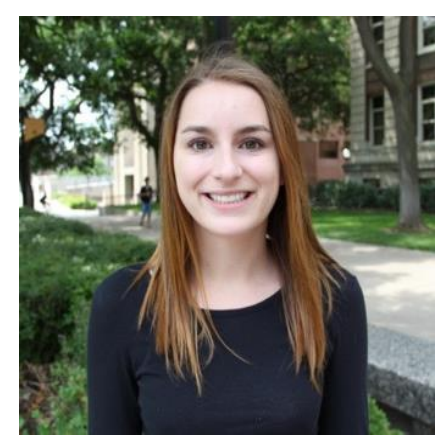

Amy Ott was born in Marshfield, Wisconsin and received her BSc degree from Carroll University in 2015. In the summer of 2015, Amy joined the Topczewski lab to undertake synthetic efforts to utilize azides in dynamic processes. 


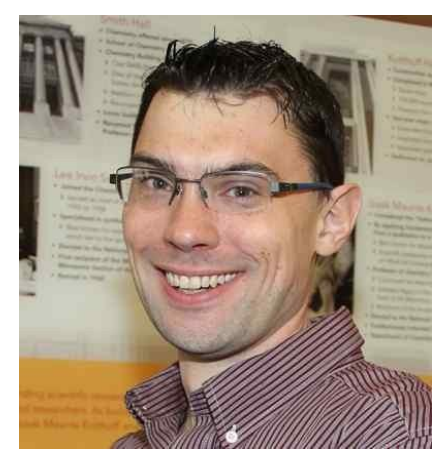

Joseph Topczewski grew up in Racine, Wisconsin and received his BSc degree from the University of Wisconsin at Parkside in 2007. He completed his PhD at the University of lowa with Prof. David Wiemer in 2011 and then conducted postdoctoral studies at lowa with Prof. Hien Nguyen and Prof. Daniel Quinn until 2013. He moved to the University of Michigan where he carried out postdoctoral studies with Prof. Melanie Sanford. In the summer of 2015, he started his independent research career at the University of Minnesota. 